\title{
Maternal mortality assessment in a tertiary care hospital in Uttar Pradesh, India
}

\author{
Urvashi Barman Singh $^{1 *}$, Shakti Jain${ }^{1}$, Yashi Srivastava1 ${ }^{1}$, Manisha Gupta $^{2}$, Meena Dayal ${ }^{1}$
}

\begin{abstract}
${ }^{1}$ Department of Obstetrics and Gynecology, MLN Medical College Prayagraj, Uttar Pradesh, India
${ }^{2}$ Superintendent In Chief (SIC), District Women Hospital, Prayagraj, Uttar Pradesh, India
\end{abstract}

Received: 12 July 2020

Accepted: 07 August 2020

\section{*Correspondence:}

Dr. Urvashi Barman Singh,

E-mail: urvashibarmansingh@gmail.com

Copyright: ( $)$ the author(s), publisher and licensee Medip Academy. This is an open-access article distributed under the terms of the Creative Commons Attribution Non-Commercial License, which permits unrestricted non-commercial use, distribution, and reproduction in any medium, provided the original work is properly cited.

\begin{abstract}
Background: Objective of this study was to calculate the maternal mortality rate in our hospital and to assess the epidemiological aspects and causes of maternal mortality to further analyse ways to reduce the maternal mortality rate (MMR).

Methods: This was a retrospective analytical study done in the department of obstetrics and gynecology, MLN Medical College and District Women Hospital, Prayagraj over a time period of 10 years i.e., October 2009 to October 2019. Retrospective analysis and evaluation of the medical records and statistics was done to find out and collect specific causes of maternal deaths in the give time period.

Results: There were 357 maternal deaths from October 2009 to October 2019. Maternal mortality rate in the study was calculated to be 498.42 per 1 lakh live births. Maximum deaths were in 21-30 years age group with multipara, unbooked and illiterate cases. Majority of the deaths reported were from direct causes of maternal mortality i.e., hemorrhage, hypertensive disorders and sepsis.

Conclusions: In the selected hospitals, the mean maternal mortality rate in the study period was $498.42 / 100000$ births. $71.4 \%$ had direct cause and $21.56 \%$ had indirect cause of maternal mortality several factors like regular antenatal visits, early identification of high-risk cases, timely referral, institutional deliveries, adequate post-partum care and follow-up can contribute to decrease the maternal mortality rate effectively.
\end{abstract}

Keywords: Causes of maternal mortality, Epidemiology, Maternal mortality rate

\section{INTRODUCTION}

Maternal death is the death of a woman while pregnant or within 42 days of termination of pregnancy, irrespective of the duration and site of the pregnancy, from any cause related to pregnancy and not from accidental causes. ${ }^{1}$ There is reduction in maternal mortality globally. Onefifth of the global burden of absolute maternal deaths is in India. $^{2}$ There is $44 \%$ fall of world's MMR in 25 years. 216 maternal deaths per lakh live birth in 2015 from 385 in 1990 showed $2.3 \%$ fall annually. ${ }^{3}$ Extensive efforts to reduce maternal mortality are made in India, however, the progress is uneven. High rate of maternal mortality is still in Uttar Pradesh and Rajasthan compared to Kerala and Tamil Nadu.

The three delays: delay in seeking care, delay in reaching care and delay in receiving adequate and appropriate care inhibit women from receiving appropriate maternal health care.

Delays in seeking care comprise of the decisions made by the pregnant women or other decision-making individuals. Decision-making individuals can include the woman's spouse and family members. ${ }^{4}$ It is due to lack of knowledge about when to seek care, inability to afford 
health care, and women needing permission from family members.

Delays in reaching care are due to limitations in transportation to a medical facility, lack of adequate medical facilities in the area.

Delays in receiving adequate and appropriate care may be because of number of trained providers and lack of appropriate supplies. ${ }^{3,4}$

Considering the lack of studies analysing the number and cause of maternal mortality especially in Uttar Pradesh, this study was done in an attempt to mainly chalk out the trend and causes of MMR in selected hospitals with tertiary care settings with the following objectives.

\section{Aims and objectives}

1. To calculate the maternal mortality rate in our hospital.

2. To describe the epidemiological aspects and causes of maternal mortality.

\section{METHODS}

This was a retrospective analytical study conducted at department of obstetrics and gynecology, MLN Medical College and District Women Hospital, Prayagraj, Uttar Pradesh, India from October 2009 to October 2019.

\section{Inclusion criteria}

All maternal deaths occurring in the hospital during the period from October 2009 to October 2019 in the department of obstetrics and gynecology MLN Medical College and District Women Hospital, Prayagraj were included in the study.

\section{Exclusion criteria}

Women that died due to life threatening conditions unrelated to pregnancy i.e., not during pregnancy or 42 days after termination of pregnancy were excluded.

Maternal mortality rate for the study period was calculated by using the formula;

$$
\text { MMR }=\frac{\text { Total number of maternal death }}{\text { Total number of live births }} \times 100000
$$

Sample collection was done from medical records. This was a retrospective analysis of data, from October 2009 to October 2019 in department of obstetrics and gynecology, MLN Medical College and District Women Hospital, Prayagraj, Uttar Pradesh, India. Data regarding maternal mortality was collected from maternal mortality Register and medical records were reviewed, their socio- demographic features, mode of delivery, diagnosis on admission, surgical intervention, ICU admission, cause of death and time of death were collected.

\section{Statistical analysis}

The collected data was entered in MS Excel and descriptive analysis was performed. The data was compiled and presented in the form of tables. The results (sociodemographic features, mode of delivery and cause of death) have been expressed as percentages. The yearwise trend of maternal mortality in the selected hospitals has been depicted in a line diagram.

\section{RESULTS}

During the study period, October 2009 to October 2019, out of the total 72,819 deliveries conducted, there were a total of 71,627 live births and 357 maternal deaths that were recorded (Table 1).

Table 1: Variables depicting the maternal outcomes of the cases investigated.

\begin{tabular}{|lll|}
\hline $\begin{array}{l}\text { Total number } \\
\text { of deliveries }\end{array}$ & $\begin{array}{l}\text { Total number } \\
\text { of live births }\end{array}$ & $\begin{array}{l}\text { Total number of } \\
\text { maternal deaths }\end{array}$ \\
\hline 72,819 & 71,627 & 357 \\
\hline
\end{tabular}

The epidemiological characteristics of maternal deaths are shown in Table 2. Maximum maternal deaths, i.e., $189(52.94 \%)$ were reported in the age group of 20 to 30 years. More deaths were reported in multiparous women $211(59.10 \%)$ as compared to $146(40.90 \%)$ in Primiparas, more maternal deaths were reported in women from rural areas $233(65.27 \%)$ as compared to women from urban areas 85 (34.73\%). Maximum maternal deaths were reported in unbooked patients, 287 $(80.39 \%)$ as compared to booked patients $70(19.60 \%)$. More than sixty percent $(61.34 \%)$ of maternal deaths were reported in illiterate women.

According to the data collected, it was observed in this study that, $280(71.47 \%)$ had direct cause of maternal mortality, resulting directly as a complication of pregnancy, including hemorrhage, eclampsia and preeclampsia, unsafe abortions and infections. 77 (21.56\%) women died due to indirect causes, that is death due to a pre-existing cause not related to pregnancy like anemia, liver, cardiac and respiratory dysfunction (Table 3).

On analysis of the data recorded, as depicted in Table 4, it was observed that out of 357 maternal mortalities, there were $113(31.65 \%)$ cases of hemorrhage, 96 (26.89\%) eclampsia and pre-eclampsia and $44(12.32 \%)$ infections, whereas $77(21.56 \%)$ women died due to indirect causes like anemia, liver, cardiac and respiratory dysfunction. It was seen that $15(4.20 \%)$ and $12(3.36 \%)$ mortalities resulted from rupture uterus and ruptured ectopic pregnancy respectively. 
Table 2: Distribution based on demographic variables.

\begin{tabular}{|llll|}
\hline Characteristics & & Number of cases $(\mathbf{n}=357)$ & Percentage \\
\hline \multirow{2}{*}{ Age (years) } & $<30$ & 189 & 52.94 \\
\cline { 2 - 4 } & $>30$ & 168 & 47.06 \\
\hline \multirow{2}{*}{ Literacy } & Illiterate & 219 & 61.34 \\
\cline { 2 - 4 } & literate & 138 & 38.66 \\
\hline \multirow{2}{*}{ Residential area } & Rural & 233 & 65.27 \\
\cline { 2 - 4 } & Urban & 85 & 34.73 \\
\hline \multirow{2}{*}{ Booked/unbooked } & Booked & 70 & 19.60 \\
\cline { 2 - 4 } & Unbooked & 287 & 40.39 \\
\hline \multirow{2}{*}{ Gravidity } & Primi & 146 & 59.90 \\
\cline { 2 - 4 } & Multi & 211 & \\
\hline
\end{tabular}

Table 3: Distribution of patient according to the cause of death.

\begin{tabular}{|lll|}
\hline $\begin{array}{l}\text { Cause of maternal } \\
\text { death }\end{array}$ & $\begin{array}{l}\text { Number of } \\
\text { patients }(\mathbf{n}=\mathbf{3 5 7})\end{array}$ & \begin{tabular}{l} 
Percentage \\
\hline Direct causes
\end{tabular} 280 \\
\hline Indirect causes & 77 & 78.43 \\
\hline
\end{tabular}

Table 4: Distribution of patients based on cause specific complications.

\begin{tabular}{|lll|}
\hline $\begin{array}{l}\text { Cause of maternal } \\
\text { death }\end{array}$ & $\begin{array}{l}\text { Number of } \\
\text { patients }(\mathbf{n}=\mathbf{3 5 7})\end{array}$ & Percentage \\
\hline APH and PPH & 113 & 31.65 \\
\hline $\begin{array}{l}\text { Hypertensive } \\
\text { disorder }\end{array}$ & 96 & 26.89 \\
\hline Anemia & 47 & 13.16 \\
\hline Infections & 44 & 12.32 \\
\hline Rupture uterus & 15 & 4.20 \\
\hline $\begin{array}{l}\text { Rupture ectopic } \\
\text { pregnancy }\end{array}$ & 12 & 3.36 \\
\hline Liver dysfunction & 12 & 3.36 \\
\hline Cardiac dysfunction & 10 & 2.80 \\
\hline $\begin{array}{l}\text { Respiratory } \\
\text { dysfunction }\end{array}$ & 8 & 2.24 \\
\hline
\end{tabular}

Table 5: Time interval between admission and death.

\begin{tabular}{|lll|}
\hline $\begin{array}{l}\text { Time between } \\
\text { admission and } \\
\text { death }\end{array}$ & $\begin{array}{l}\text { Number of } \\
\text { patients }(\mathbf{n}=\mathbf{3 5 7})\end{array}$ & Percentage \\
\hline $\mathbf{2 4}$ hours & 247 & 68.27 \\
\hline $\mathbf{2 4}$ hours & 110 & 31.73 \\
\hline
\end{tabular}

It was observed that among 357 maternal deaths recorded, 247 (68.27\%) patients expired within 24 hours of admission and $99(31.73 \%)$ deaths were reported in anytime period after 24 hours (Table 5).

\section{DISCUSSION}

Maternal mortality is an indicator of reproductive health of the society. High incidence of maternal deaths reflects poor quality of maternal services, late referral and low socioeconomic status of the community. The mean Maternal mortality rate in the study period was 498.42/100000 births. The current maternal mortality ratio (MMR) in India is $122 / 100,000$ live births. ${ }^{4}$ This study has comparatively high MMR, which could be due to the fact, that our hospital is a tertiary care hospital and receives a lot of complicated referrals from rural areas of Prayagraj at a very late stage.

In this study, $52 \%$ of maternal deaths were in the age group of 20 to 29 years, as highest numbers of births are reported in this age group. Similarly, $56.66 \%$ of maternal deaths were reported in multiparous patients. More maternal deaths were reported in women from rural areas $(69.16 \%)$, unbooked patients $(83.33 \%)$, illiterate women (65\%), and women belonging to low socioeconomic status. (83.33\%) All this study findings in the study were similar to studies by Jain et al, Jadhav et al, Pal et al, and Onakewhor et al..$^{5-8}$

It was observed that $71.47 \%$ of maternal deaths were due to direct causes. Hemorrhage $(31.41 \%)$, eclampsia $(27.56 \%)$, and sepsis $(12.55 \%)$ were the major direct causes of maternal deaths. This finding was consistent with studies by Jain et al, Jadhav et al, Pal et al, Onakewhor et al, and Shah et al..$^{5-9}$

Even today large number of maternal deaths is due to the classical triad of hemorrhage, sepsis, and eclampsia. ${ }^{10}$ All these are preventable causes of maternal mortality provided the treatment is instituted in time. Unfortunately, in many cases, patients were referred very late, in critical condition, unaccompanied by health care worker. Most of these deaths are preventable if patients are given proper treatment at periphery and timely referred to higher centers. Training of health workers and staff nurses working in rural areas and skilled attendant at birth training gives path of hope for reducing maternal mortality.

Indirect causes accounted for $28.52 \%$ of maternal deaths in this study. Jaundice, heart disease and respiratory diseases were responsible for $2.88 \%, 2.56 \%$, and $1.25 \%$ 
of maternal deaths, respectively. These findings were consistent with studies by Jain et al, Jadhav et al, Pal et al and Onakewhor et al. ${ }^{5-8}$

Maternal deaths can be prevented by improving the health care facilities in rural areas by ensuring round the clock availability of facility for primary management. Most importantly, early detection of high-risk pregnancies and referring them to a tertiary center at the earliest can reduce the complications of high-risk pregnancies. National Rural Health Mission (NRHM) can also play an integral role in reducing maternal mortality by advocating and implementing institutional deliveries and timely referral of high-risk cases.

\section{CONCLUSION}

In the selected hospitals, the mean maternal mortality rate in the study period was $498.42 / 100000$ births. $71.4 \%$ had direct cause and $21.56 \%$ had indirect cause of maternal mortality. $68.27 \%$ of maternal mortalities occurred within 24 hours and $31.73 \%$ after 24 hours. As women have gained access to family planning and skilled birth attendance with backup emergency obstetric care, the global maternal mortality ratio has reduced significantly. Although attempts have been made in improving the status of maternal care, there is much room for improvement, particularly in under developed regions. Instituting integrated maternal health services with emphasis on primary health care and emergency obstetric care can achieve remarkable improvement in maternal and perinatal outcome.

Funding: No funding sources

Conflict of interest: None declared

Ethical approval: The study was approved by the Institutional Ethics Committee

\section{REFERENCES}

1. World Health Organization. Health statistics and information systems. Maternal mortality ratio (per 100,000 Live births). Geneva: WHO; 2014.
2. Montgomery AL, Ram U, Kumar R, Jha P. Million death study collaborators. Maternal mortality in India: causes and healthcare service use based on a nationally representative survey. PloS One. 2014;9(1):e83331.

3. Calvello EJ, Skog AP, Tenner AG, Wallis LA. Applying the lessons of maternal mortality reduction to global emergency health. Bulletin World Health Organization. 2015;93:417-23.

4. Thaddeus S, Maine D. Too far to walk: maternal mortality in context. Social Sci Medi. 1994;38(8):1091-110.

5. Jain M, Maharahaje S. Maternal mortality: a retrospective analysis of 10 years in a tertiary hospital. Indian J Prev Soc Med. 2003;34(3-4):10311.

6. Jadhav AJ, Rote PG, Maternal mortality-changing trends. J Obstet Gynecol India. 2007:57(5):398-400.

7. Pal A, Ray P, Hazra S, Mondal TK. Review of changing trends in maternal mortality in a rural medical college in West Bengal. J Obstet Gynecol India. 2005:55(6):521-4.

8. Onkewhor JU, Gharoro EP. Changing trends in Maternal Mortality in a developing country. Niger J Clin Pract. 2008;11(2):111-20.

9. Shah RJ, AliI, Banday A, Fazili A, Khan I. Analysis of maternal mortality in a small teaching hospital attached to tertiary care hospital. Indian $\mathbf{J}$ Community Med. 2008;33(4):260-2.

10. Murthy BK, Murthy MB, Prabhu PM. Maternal mortality in a tertiary care hospital: a 10-year review. Int J Prev Med. 2013;4(1):105-9.

Cite this article as: Singh UB, Jain S, Srivastava Y, Gupta M, Dayal M. Maternal mortality assessment in a tertiary care hospital in Uttar Pradesh, India. Int J Reprod Contracept Obstet Gynecol 2020;9:3814-7. 